\title{
Numerical Model Analysis of Myring-Savonius Wind Turbines
}

\author{
M. SALEH ${ }^{1}$, F. SZODRAI ${ }^{2}$ \\ ${ }^{1}$ University of Debrecen, Faculty of Engineering, Department of Mechanical Engineering, \\ mhmodsalh84@gmail.com \\ ${ }^{2}$ University of Debrecen, Faculty of Engineering, Department of Building Services and Building Engineering, \\ szodrai@eng.unideb.hu
}

Abstract. Nowadays the importance of renewable energy is growing, and the utilization of the low wind energy potential is getting crucial. There are turbines with low and high tip speed ratio. Turbines with low tip speed ratio such as the Savonius wind turbine can generate adequate amount of torque at low wind velocities. These types of turbines are also called drag machines. The geometry of the blade can greatly influence the efficiency of the device. With Computational Fluid Dynamics (CFD) method, several optimizations can be done before the production. In our paper the Savonius wind turbine blade geometry was based on the so-called Myring equation. The primary objective of this paper was to increase the power coefficient by modelling the effect of the wind on the turbine blade. For the sake of simplicity, a 2D cross-sectional area was investigated in the simulation with ANSYS CFX 19.1.

Keywords: Savonius, wind turbine, CFD, CFX, Myring Equation.

\section{Introduction}

There are two types of wind turbines: the widely spread "lift wind turbines", and the less popular "drag wind turbines" [1]. For the wind turbines, the physical upper limit for the energy conversion rate is known as Betz law [2]. The Betz law states that the power coefficient can reach at most $59.3 \%$ in an undisturbed wind stream [3]. Even that the theoretical limit can be exceeded using an ideal-closed wind turbine system, but it is reported that "drag machines" are less efficient than "lift machines" [4]. Drag wind turbines are less likely in their current state, to exceed the limit of lift wind turbines [4]. On other hand "drag wind turbines"-specially Savonius wind turbine-have the following advantages over other types of wind turbines [5]:

1-ability to operate under complex turbulent flows.

2-low rotation speed and noise emission.

3-high starting torque and starting performance.

4-simple structure and low cost.

Changing the shape of the Savonius turbine's blade can improve its performance. Kamoji et al, and Kacprzak et al adapted the Bach type blades for Savonius turbine and studied the effect of geometrical 
parameters on the performance. Their wind tunnel and numerical simulation indicated that that the power coefficient was increased by up to $16 \%$ for the modified Savonius turbine given the optimal geometrical parameters compared with that of semi-circular blades [6]. Traditional Savonius wind turbines generate a high drag force which can limit the efficiency of the turbine [7]. Reducing these forces can enhance the performance of the turbine. The main goal of this study is to decrease the drag force acting on the convex surface of the blade.

\section{Blade Shape Modification}

The Myring Equation is commonly used to design the nose of autonomous under water vehicles (AUVs) and has proven to give an ideal coefficient of drag [5]. The Myring Equation for designing the nose of an AUV is:

$$
\mathbb{Y}=\mathrm{b} \times\left[1-\left(\frac{\mathbb{X}}{\mathrm{a}}\right)^{2}\right]^{1 / \mathrm{n}}
$$

In this paper we focused on the effect that the factor (a) had on the magnitude of the drag force acting on the convex surface of the blade. For this purpose, we hold $n=2, b=0.25 \mathrm{~m}$ and (a) changed from $0.375 \mathrm{~m}$ to $0.450 \mathrm{~m}$ which determined elliptical surface.

\section{Numerical Method}

2D (1 mesh thick) steady flow simulation was carried out to reduce the time and the fluid was the air with density $1.2 \mathrm{~kg} \mathrm{~m}^{-3}$. To allow for the full development of the upstream flow, the computational domain (Figure 1.) was $8 \mathrm{~m}$ long $2 \mathrm{~m}$ wide. The blade was placed midway between the top and the bottom of the tunnel. Also, the symmetry boundary was applied to avoid the wall effect. For every blade, the simulations were conducted at three different velocities which were $1 \mathrm{~m} \mathrm{~s}^{-1}, 1.5 \mathrm{~m} \mathrm{~s}^{-1}$ and $2 \mathrm{~m} \mathrm{~s}^{-1}$. Figure 2. shows the computational grid which was generated using the MESH tool in ANSYS 19.1. The size of the mesh was $0.02 \mathrm{~m}$. The inflation was carried out around the blade surfaces to increase the accuracy of the calculations. The number of the layers was 25 and the rate of growth was 1.2. For turbulence modelling, a shear stress transport was applied.

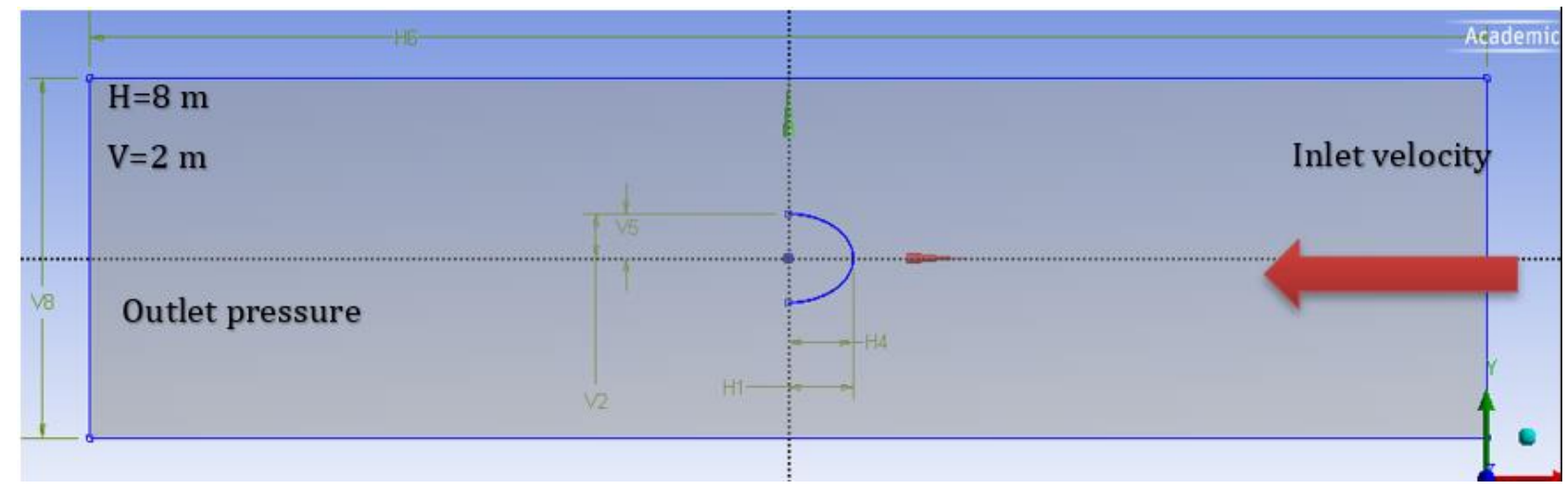

Figure 1. The computational domain 


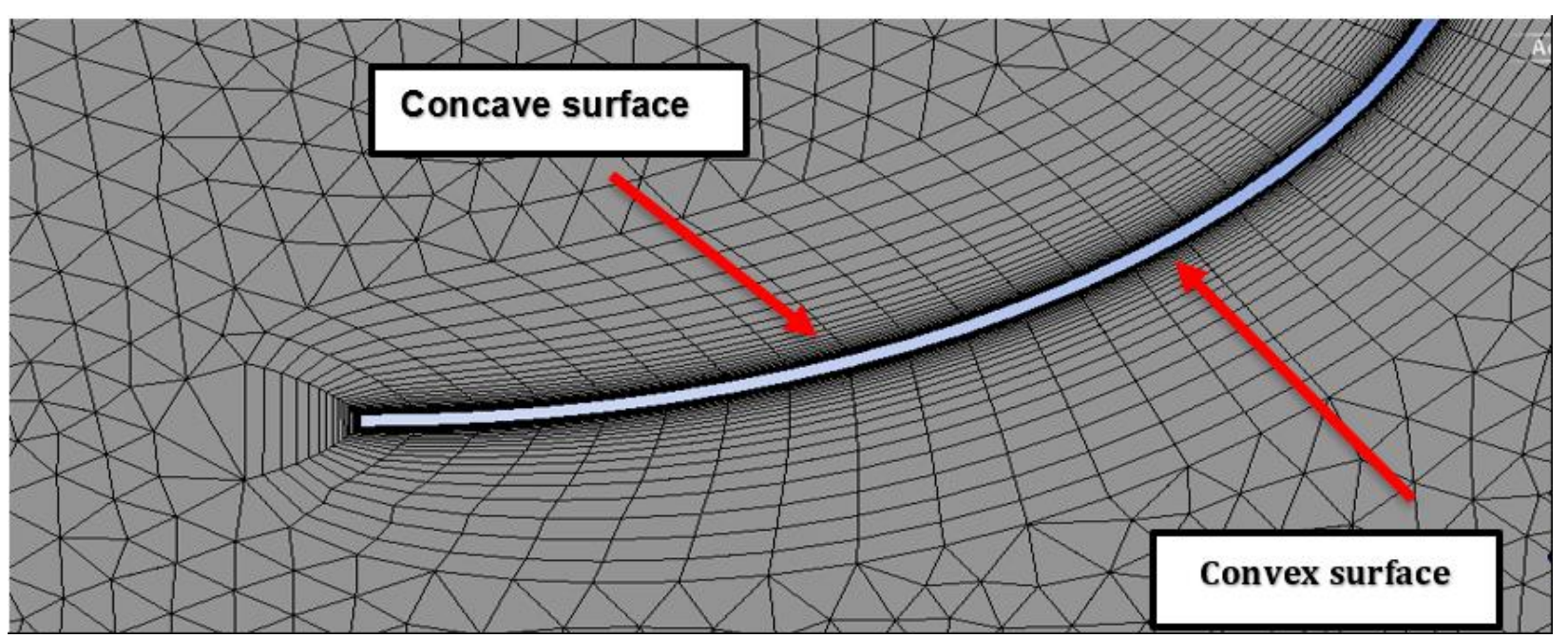

Figure 2. The computational grid

\section{Result and Discussion}

Table 1. shows the values of the drag force acting on the convex surface of the blade with respect to the factor (a) at three different velocities. All the results in the table are represented as graphics to illustrate the behaviour of the drag force as a function of the factor (a) at three different velocities. Figure 3. shows that the drag force increases as the factor (a) increases until it reaches the highest value which is $39.3010^{-4} \mathrm{~N}$ when a $=0.425 \mathrm{~m}$. This value drops slightly and reaches $36.0810^{-4} \mathrm{~N}$ at the fourth blade. In figure 4 ., the most significant result is that the drag force remains approximately the same between $\mathrm{a}=0.375 \mathrm{~m}$ and $\mathrm{a}=0.400 \mathrm{~m}$, and it hits a peak when $\mathrm{a}=0.425 \mathrm{~m}$. Between the third and fourth blade, the drag force drops sharply to reach the lowest value. At velocity $2 \mathrm{~m} \mathrm{~s}^{-1}$ (Figure 5.), the drag force rises roughly linearly when factor (a) changes from $0.375 \mathrm{~m}$ to $0.425 \mathrm{~m}$. Figure 6 shows that the highest value of the pressure appears on the peak of the blade.

Table 1. The drag force acting on the convex surface

\begin{tabular}{llll}
\hline Case & $\mathbf{V = 1} \mathbf{~ m ~ s}^{-1}$ & $\mathbf{V = 1 . 5} \mathbf{~ m ~ s}^{-1}$ & $\mathbf{V = 2} \mathbf{~ m ~ s}^{-1}$ \\
\hline $\mathrm{a}=0.375 \mathrm{~m}$ & $32.6710^{-4} \mathrm{~N}$ & $83.2710^{-4} \mathrm{~N}$ & $133.9210^{-4} \mathrm{~N}$ \\
\hline $\mathrm{a}=0.400 \mathrm{~m}$ & $34.5410^{-4} \mathrm{~N}$ & $83.1210^{-4} \mathrm{~N}$ & $140.7910^{-4} \mathrm{~N}$ \\
\hline $\mathrm{a}=0.425 \mathrm{~m}$ & $39.3010^{-4} \mathrm{~N}$ & $86.1510^{-4} \mathrm{~N}$ & $148.9610^{-4} \mathrm{~N}$ \\
\hline $\mathrm{a}=0.450 \mathrm{~m}$ & $36.0810^{-4} \mathrm{~N}$ & $80.4010^{-4} \mathrm{~N}$ & $150.9310^{-4} \mathrm{~N}$ \\
\hline
\end{tabular}


International Journal of Engineering and Management Sciences (IJEMS) Vol. 4. (2019). No. 1

DOI: 10.21791/IJEMS.2019.1.23.

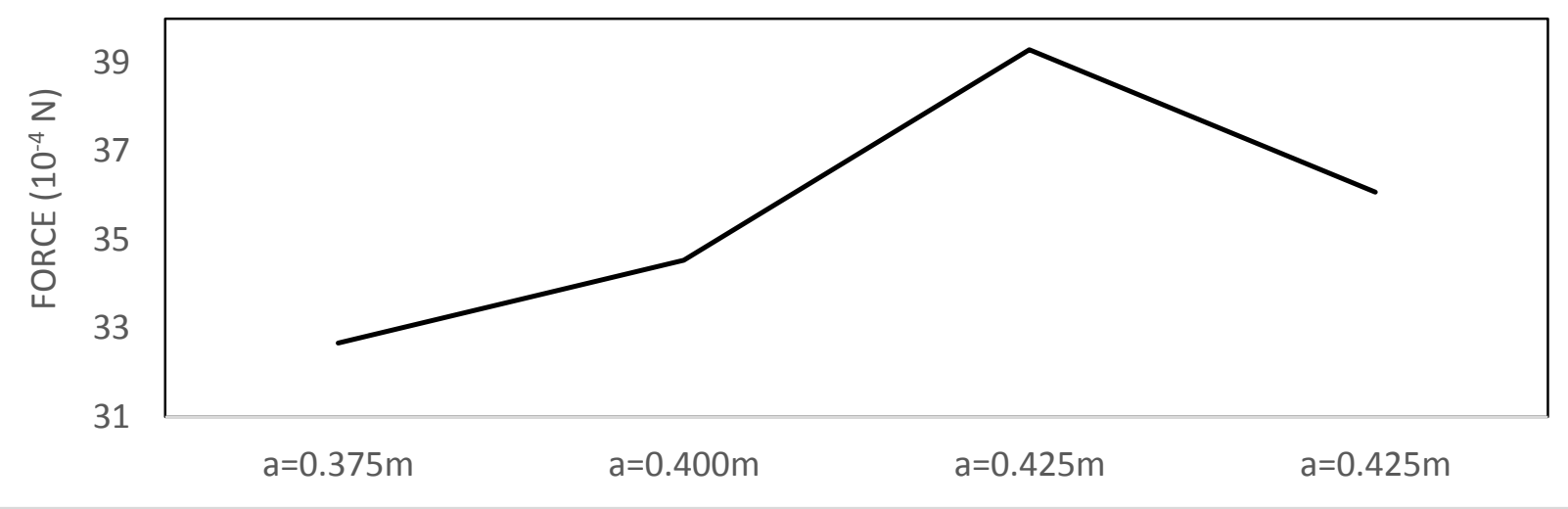

Figure 3. The drag force as a function of the factor (a) at velocity $1 \mathrm{~m} \mathrm{~s}^{-1}$

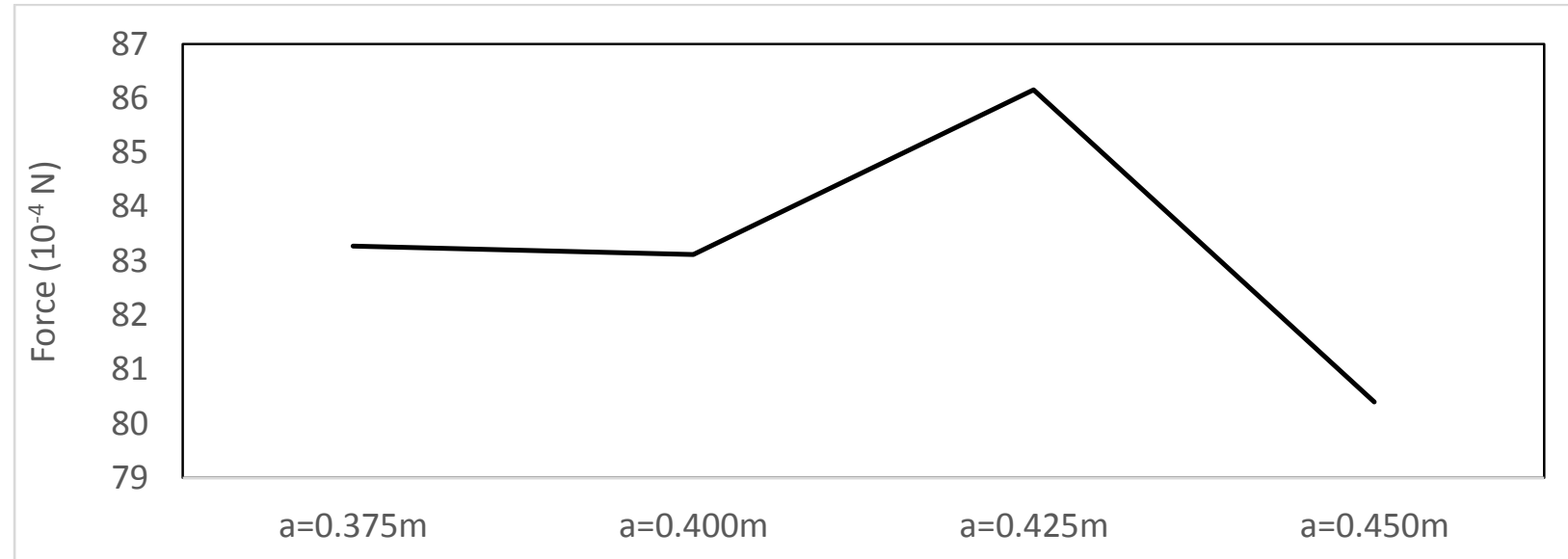

Figure 4. The drag force as a function of the factor (a) at velocity $1.5 \mathrm{~m} \mathrm{~s}^{-1}$

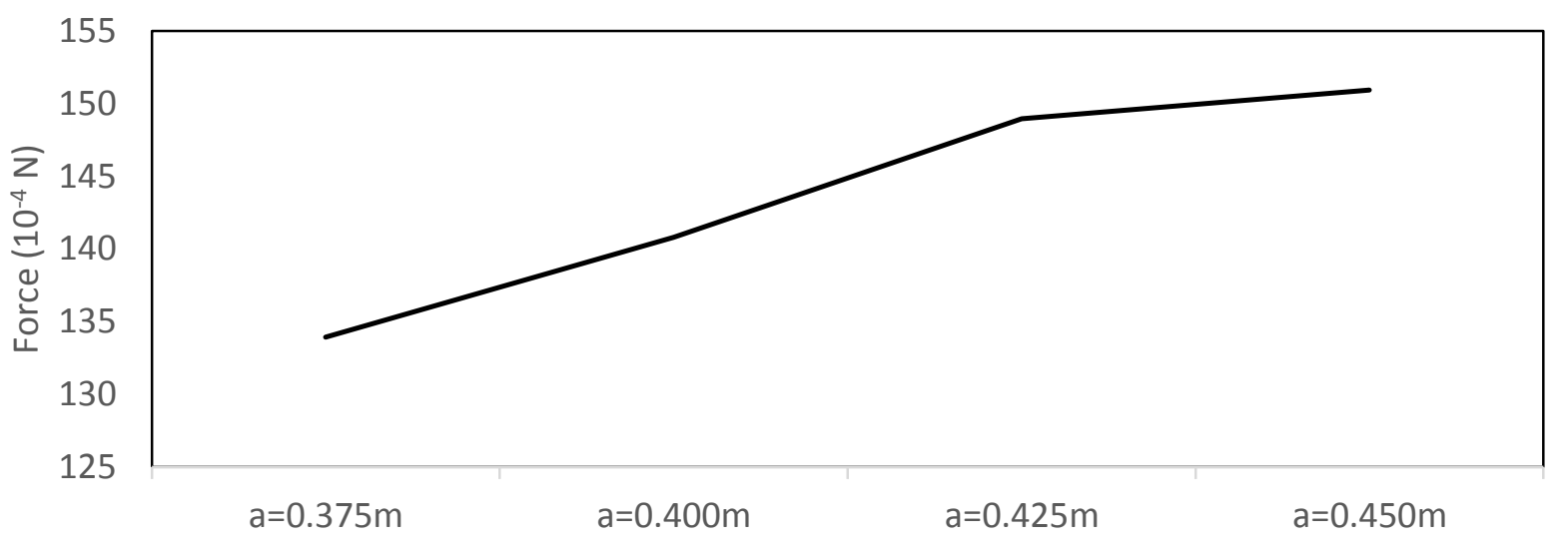

Figure 5. The drag force as a function of the factor (a) at velocity $2 \mathrm{~m} \mathrm{~s}^{-1}$ 


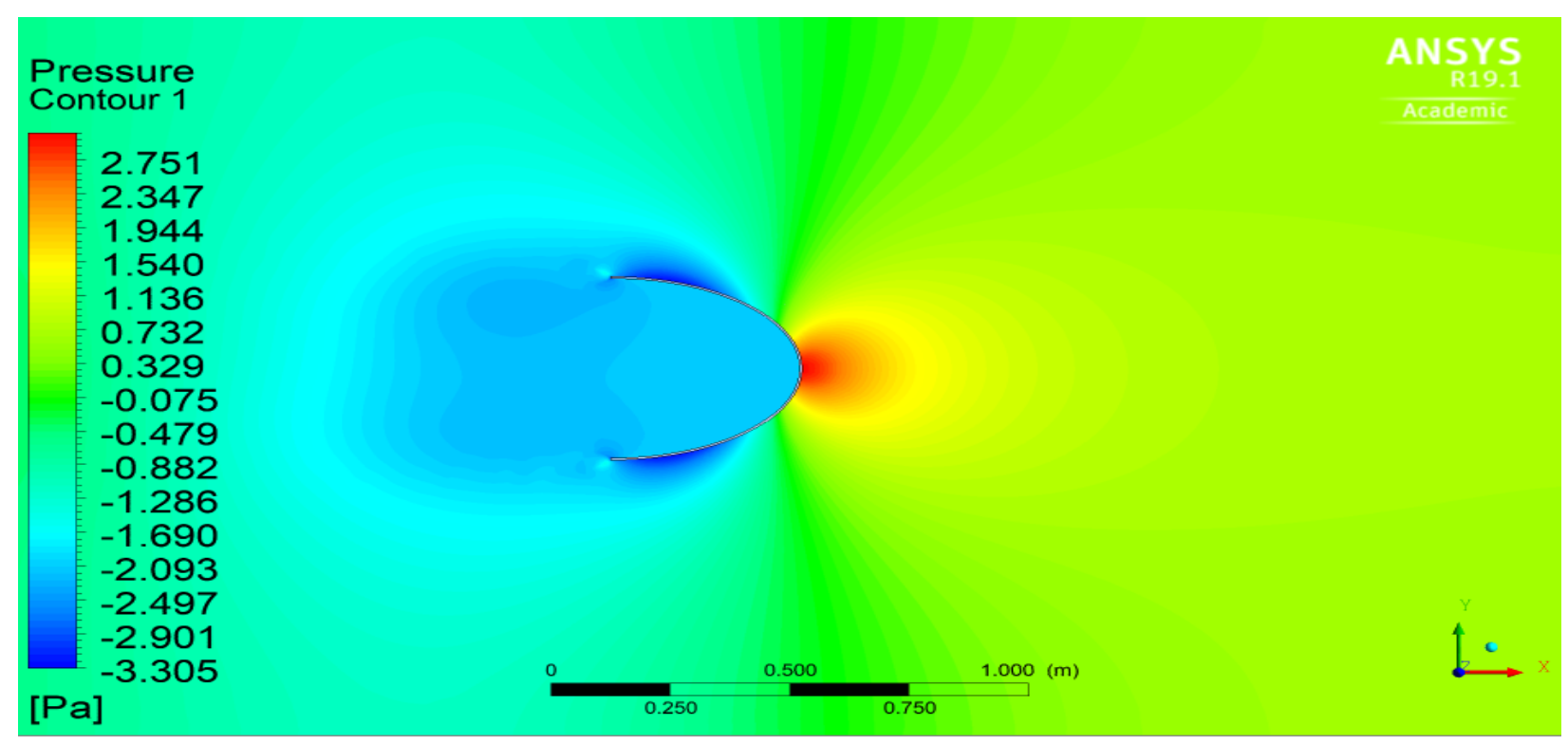

Figure 6. Pressure distribution

\section{Conclusion}

The numerical simulations had been carried out to investigate the drag force acting on the convex surfaces of four modified Myring-Savonius blades at three different velocities. The following results were obtained:

1) At velocities $1 \mathrm{~m} \mathrm{~s}^{-1}$ and $2 \mathrm{~m} \mathrm{~s}^{-1}$, the lowest value of the drag force appeared on the first blade with $\mathrm{a}=0.375 \mathrm{~m}$.

2) At velocity $1.5 \mathrm{~m} \mathrm{~s}^{-1}$, the lowest value of the drag force appeared on the fourth blade with $\mathrm{a}=0.450 \mathrm{~m}$.

Although the drag force acting on the surface of the first blade is not the lowest at any velocity, taking into consideration the changes in wind speed, the first type is recommended to be used.

\section{References}

[1] J. Twidell - W. Routledge (2015) Renewable energy resources, 1. 3., Abingdon, Oxon: Routledge.

[2] F. Thönnißen - M. Marnett - B. Roidl - W. Schröder (2016) A numerical analysis to evaluate Betz's Law for vertical axis wind turbines. 1. 753, 1. 022056, 2016.

[3] M. Ragheb - A. Ragheb (2011) Wind Turbines Theory - The Betz Equation and Optimal Rotor Tip Speed Ratio. in Fundamental and Advanced Topics in Wind Power.

[4] E. Aymane - H. Darhmaoui - N. Sheikh (2017) Savonius Vertical Wind Turbine: Design, Simulation, and Physical Testing. Ifrane: Al Akhawayn University.

[5] T. Wen-long - B. Song - J. H. VanZwieten - P. Pyakurel (2015) Computational Fluid Dynamics Prediction of a Modified Savonius Wind Turbine with Novel Blade Shapes. Energies. 1. 8, pp. 79157929. 
International Journal of Engineering and Management Sciences (IJEMS) Vol. 4. (2019). No. 1

DOI: 10.21791/IJEMS.2019.1.23.

[6] C. M. Chan - H. L. Bai - D. Q. He (2018) Blade shape optimization of the Savonius wind turbine using a genetic algorithm. Applied Energy, 1. 213, 1. 1, pp. 148-157.

[7] Institutes of Technology, [Online]. Available: https://nptel.ac.in/course.php. [2018]. 